\title{
Corporate Yoga: An Empirical Study to Overcome the Problem of Chronic Back-pain among Employees of IT Sector
}

\author{
Sheetal, Independent Researcher, M.A. in Yoga (UGC-NET), India. sheetalkhatri1995@gmail.com \\ Neeru Devi, Independent Researcher, M.Phil, M.Com (UGC-NET), India. \\ neerukhatricommerce@gmail.com
}

\begin{abstract}
Background - Back pain is a very huge problem faced by employees in IT sector. Many employees are not able to perform their work effectively and efficiently because of it. Yoga is an emerging tool in curing back pain. It has also been used at workplace for various health benefits i.e. mental, physical \& psychological and it is economical as well.

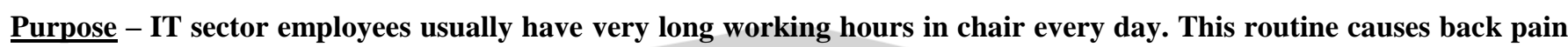
in many employees. Some cases of back pain are normal and only remain for short time, but in some cases this back pain becomes chronic in nature. This chronic back pain prevents the employees by doing many tasks in their daily life. Working capacity also diminishes by back pain. In this paper, the effectiveness of Yoga will be studied in respect to back pain in IT sector employees.

Methodology - A group made of 50 employees ( 25 female \& 25 male) from IT sector were chosen as the experimental group for this study. The participants made to do specific Yoga practices for three months to identify the effectiveness of Yoga in back pain management.

Findings - After the intervention of 90 days yoga practice, it was found that yoga is very helpful in curing chronic back pain and improving quality of life. Yoga is revealed as great therapy in curing back pain and disability.

Practical Implications - This research study recommends that IT companies should organize yoga classes time to time or on daily basis in break time, in order to keep the employees fit, less stressed and lower risk of chronic back pain \& other health hazards among them. It is also recommended that these yoga classes should be host by well qualified yoga teachers/instructors so that full benefits can be enjoyed by the employees.
\end{abstract}

Key Words: Back-pain, Employees, Yoga.

\section{INTRODUCTION}

In today's era lifestyle is becoming inactive day by day. This inactive lifestyle is attracting many health problems \& consequences. This risk becomes even higher when someone have desk job. Sitting on chair continuously for long hours creates many health problems; back pain is one of them. Moreover 60-80 percent people experience some kind of back pain in their life span. In general back pain may arise due to many reasons, some of them include lifting heavy objects without correct technique, some infection, fracture, osteoarthritis, bad posture, sitting on chair for long hours, obesity, emotional shock, continuous use of high heels, influenza, kidney problems, some women's health issues and prostate gland disease etc. In case of IT sector personnel's, their job profile mostly include sitting on one place while working in desktops/laptops. This kind of job profile leads them to severe back pain if not taken care of oneself properly while working. One should get out of the working chair time to time to relax the body, but the work burden doesn't allow them to do so. They also didn't get time to cope-up with this inactivity and do some exercise because most of their day time spent at their respective workplaces. Because of the continuous long working hours, the pressure on the spine rises and blood flow decreases in muscles \& nerves of the back, this leads the IT employees to severe back pain. When this back pain becomes chronic in nature, it creates many problems in daily life. The person suffering with chronic back pain even feels the pain while coughing, 
sneezing, bowel movement, walking, sitting; slight bending and any kind of extra stress make the pain double. This kind of back pain rises in the evening. Yoga is cure to many diseases and by practicing yoga one can achieve desirable health benefits (Sheetal 2020). Yoga is great therapy as it's convenient, economical and with less degree of side-effects. People suffering from chronic back pain can do yoga as yoga poses are relaxing and soothing even during the pain. Yoga can be practiced in the break time at workplace and after the work at home in evening also. Yoga asanas i.e. Makrasana, Advasana, Matsyakridasana, Sarpasana, Ardhshalbhasana, Bhujanagasana, Vajrasana, Dvikonasana and Marjariasana are very beneficial in chronic back pain. Dhyana (Meditation) technique of Ajapa-Japa and Pranayamas i.e. Nadi-shodhana Pranayama and Bhramari Pranayama are also helpful in curing chronic back pain. Balanced diet and active lifestyle can also be practiced along with yoga to get better results (Sheetal 2020).

\section{LITERATURE REVIEW}

Tilbr, Chuang \& Trewhela (2011) conducted a study to compare usual care of lower back pain with application of yoga to reduce back pain. It was found in the study that yoga had a significant effect as compare to usual care for back pain. 12-week yoga program was found effective to reduce back pain in adults. Aboagye, Karlsson, Hagberg \& Jensen (2015) also conducted a study to identify the effectiveness of medical yoga as intervention in comparison of self-care advice for low back pain. A 6-week yoga therapy was found as cost-effective and efficient source for low back pain. Employees have very high workloads in today's era of globalization. This leads them to many health problems (Devi \& Sheetal 2020). Sawyer, Martinez \& Warren (2012) organized a study with the objective to analyze previous literature to identify the effect of yoga in chronic low back pain. It was found that practicing yoga can reduce back pain and it is also helpful to increase functional ability of people suffering from low back pain. Using more technology i.e. laptops and smartphones etc. causes neck and back pain (Malik \& Devi 2018). Shivaji \& Shivaji (2019) conducted a research study to analyze the effectiveness of Yoga on lower back pain. It was found that Yoga improves the quality of life and helpful in curing back pain. Yoga therapy is very effective in back pain, as it works at all levels i.e. physical, psychological and emotional (Jadhav, Biradar \& Bansode 2020). Yoga is safe to practice and helpful in reducing back pain \& disability (Chang et al. 2016). Bhatta, Tekur, Tikhe \& Nagendra (2015) again conducted a study to analyze the effect of yoga on chronic low back pain (CLBP). 35 patients with CLBP were taken as experimental group. It was concluded that yoga is helpful in back pain management. Sunil \& Kumari (2016) studied upon a research to measure the effect of yoga module on low back pain in IT professionals. The results proved that there is significant relationship between yoga and back pain, yoga reduces back pain, anxiety and depression among the subjects.

\section{Objectives}

The objective of this paper is to explore the effectiveness of yoga as a preventive measure for chronic back pain among IT sector employees. This paper will attempt to study the effects of Asanas, Pranayama and Meditation on back pain and also try to figure out the effect of yoga in improving quality of life among the employees facing chronic back pain.

\section{MATERIALS AND MEthodS}

People who were working in different companies of IT sector in Delhi region were taken as experimental group of the present study. Every participant of this study was more or less suffering with chronic back pain. Each of the participants was volunteers as they wanted to try this innovative and cost-effective therapy. All of the participants were sitting for 8-10 hours continuously on the desk with just a small break. They were facing many problems due to this back pain in their daily chores and also poor life quality because of it. Descriptive statistics was used during the study.

\section{Sampling Technique}

Deliberative sampling technique was used in this research study. Participants were deliberatively selected from specific region and specific walk of life. 50 participants from Delhi (India) were taken as experimental group of the present study. Half of the participants were female $\&$ half were male ( 25 female \& 25 male). Their ages were between 28-42 years. All the participants were IT professionals. Every participant was a volunteer in this study.

\section{Inclusive criteria}

IT sector employees who have chronic back pain were included for achieving the objectives of the study. All the employees were volunteers for this study. They saw yoga as a very effective and more economical therapy for their health problems. They were looking for something more adaptable and with fewer side effects, $\&$ wanted to try yoga as it has both the qualities.

\section{Exclusion criteria}

People from outside Delhi and working in other walks of life other than IT sector were excluded. IT sector employees who were facing chronic back pain with other major health hazards and who were constantly under modern medical treatment for chronic back pain were excluded. These exclusions were made as per the demand of the study and to achieve the goal of the study.

\section{Intervention}

Single experimental group design method was used in this study. All the participants were made to practice the Yogic regime i.e. Asanas, Pranayamas and Meditation for chronic back pain. The experimental group practiced these yoga 
exercises continuously for 3 months except Sundays in order to attain maximum health benefits and the goal of the study.

Table 1: Intervention Schedule

\begin{tabular}{|c|c|c|c|}
\hline $\begin{array}{l}\text { S. } \\
\text { No. }\end{array}$ & $\begin{array}{l}\text { Yogic } \\
\text { Practice }\end{array}$ & $\begin{array}{c}\text { Timing } \\
\text { (In } \\
\text { Minutes) }\end{array}$ & Names of the practices \\
\hline $\mathbf{1}$ & Meditation & 5 & Guided Meditation \\
\hline 2 & Prayer & 5 & Beginning Prayer \\
\hline 3 & $\begin{array}{l}\text { Shukshma } \\
\text { vyayam }\end{array}$ & 10 & Stretching \\
\hline 4 & Asanas & 20 & $\begin{array}{l}\text { Sarpasana, Ardh-shalabhasna, Saral- } \\
\text { Dhanurasana, } \\
\text { Ushtrasana, } \\
\text { Meruvakrasana, } \\
\text { Garudasana \& Marjariasana }\end{array}$ \\
\hline 5 & Pranayama & 10 & $\begin{array}{l}\text { Nadi-Shodhana Pranayama \& } \\
\text { Bhramari Pranayama }\end{array}$ \\
\hline 6 & $\begin{array}{l}\text { Mantra- } \\
\text { Meditation }\end{array}$ & 10 & Ajapa-Japa \\
\hline 7 & Relaxation & 20 & Makrasana/Advasana/Matsyakridasana \\
\hline \multicolumn{4}{|c|}{ Total Time of the Practice } \\
\hline
\end{tabular}

Total one hour and twenty minute session was arranged for participants with individual time frame for each yoga practices. All the Asanas were practiced under guidance. Meditation \& prayer were done in Vajrasana and some participants used pillow to help the spine at initial stage of the study. After some days, the participants were able to sit without any help \& in correct postures and improvement was noticed meanwhile the study also.

\section{Procedures}

This study was conducted in capital region of India (Delhi). All 50 participants (25 females \& 25 males) strictly practiced the selected yogic regime during the course of study. The outcomes were assessed before and after the study by using questionnaires to analyze the difference if any. Data was collected from the participants through questionnaires, before and after the last day of Yoga practice and analyzed for achieving the objectives.

\section{Result \& Discussion}

A total number of 25 participants with chronic back pain was part of this study. All of them belonged to IT sector and were middle-aged. Each one of them was facing many problems because of the intensity of back pain. Yoga was the intervention tool of this research. The objective of this paper was to analyze the effect of different yoga practices on chronic back pain and the quality of life among the participants. For achieving the objectives of the study, the participants practiced yoga for three consecutive months. Before and after the $90^{\text {th }}$ day of intervention, the data was collected from the participants by using questionnaires. The before and after results of study are as follows:

Table 2: (Statistics of before/after results)

\begin{tabular}{|l|l|l|l|}
\hline Before & \multicolumn{4}{|l|}{ Tick the right option } \\
\hline Statement & Mild & Severe & Very Severe \\
\hline How severe is your back pain? & &
\end{tabular}

\begin{tabular}{|c|c|c|c|}
\hline & $10 \%$ & $28 \%$ & $62 \%$ \\
\hline \multicolumn{4}{|l|}{ After } \\
\hline Statement & \multicolumn{3}{|c|}{ Tick the right option } \\
\hline How severe is your back pain? & Mild & Severe & Very Severe \\
\hline & $76 \%$ & $14 \%$ & $10 \%$ \\
\hline
\end{tabular}

In this table, the intensity of the back pain was analyzed. Most of the participants were suffering from high intensity of back pain. This pain was affecting their life very much. Personal as well as professional life was at risk because of it. After the intervention of yoga, many of the participants were feeling relieved of the chronic back pain. Only a few of them were less relieved but most of them were feeling less pain because of yoga practice.

Table 3: (Statistics of before/after results)

\begin{tabular}{|l|c|c|}
\hline Before & \multicolumn{2}{|l|}{ Tick the right option } \\
\hline Statement & Yes & No \\
\hline $\begin{array}{l}\text { I stay at home most of the time because of my } \\
\text { back pain. }\end{array}$ & $86 \%$ & $14 \%$ \\
\hline & Tick the right option \\
\hline After & Yes & No \\
\hline Statement & $12 \%$ & $88 \%$ \\
\hline $\begin{array}{l}\text { I stay at home most of the time because of my } \\
\text { back pain. }\end{array}$ & \\
\hline
\end{tabular}

In table 3 , the effect of back pain on quality of life was analyzed. Except workplace, the participants weren't visiting many places because of chronic pain. They were spending most of their time at home. After continuous yoga practice, most of them were feeling relieved and started visiting places as they do before suffering from back pain.

\section{Table 4: (Statistics of before/after results)}

\begin{tabular}{|l|c|c|}
\hline Before & \multicolumn{2}{|c|}{ Tick the right option } \\
\hline Statement & Yes & No \\
\hline $\begin{array}{l}\text { Because of my back pain, I am not doing any of } \\
\text { the jobs that I usually do around the house. }\end{array}$ & $80 \%$ & $20 \%$ \\
\hline \multicolumn{3}{|l|}{ Tick the right option } \\
\hline After & Yes & No \\
\hline Statement & $30 \%$ & $70 \%$ \\
\hline $\begin{array}{l}\text { Because of my back pain, I am not doing any of } \\
\text { the jobs that I usually do around the house. }\end{array}$ & & \\
\hline \multicolumn{2}{|l|}{}
\end{tabular}

In this table, the effect of back pain on productivity was analyzed. Before the intervention of yoga, the participants were not doing chores around home as they normally do before they had this pain. After the intervention, the participants has less pain as compared to before and they started doing usual works at home on their own without any help.

Table 5: (Statistics of before/after results)

\begin{tabular}{|l|c|c|}
\hline Before & \multicolumn{2}{|c|}{ Tick the right option } \\
\hline Statement & Yes & No \\
\hline $\begin{array}{l}\text { Because of my back, I lie down and rest more } \\
\text { than often. }\end{array}$ & $82 \%$ & $18 \%$ \\
\hline \multicolumn{3}{|l|}{ Tick the right option } \\
\hline After & Yes & No \\
\hline Statement & $22 \%$ & $78 \%$ \\
\hline $\begin{array}{l}\text { Because of my back, I lie down and rest more } \\
\text { than often. }\end{array}$ & & \\
\hline \multicolumn{2}{|l|}{}
\end{tabular}


In this table, the effect of back pain on normal resting time was analyzed. When the participants started suffering from chronic back pain, their resting time also started increasing as well. They were resting much more time than usual when the study began. After the intervention, the participants were feeling already relaxed as the pain reduced and they were not spending extra time to relax than usual.

Table 6: (Statistics of before/after results)

\begin{tabular}{|l|c|c|}
\hline Before & \multicolumn{2}{|c|}{ Tick the right option } \\
\hline Statement & Yes & No \\
\hline I sleep less well because of my back. & $76 \%$ & $24 \%$ \\
\hline & \multicolumn{3}{|l|}{} \\
\hline After & \multicolumn{2}{|c|}{ Tick the right option } \\
\hline Statement & Yes & No \\
\hline I sleep less well because of my back. & & \\
\hline & $8 \%$ & $92 \%$ \\
\hline
\end{tabular}

Here, the effect of chronic back pain on sleep quality was analyzed. Because of back pain, the participants of the study were having very less sleep than usual and that also of poor quality. After the intervention, the sleep quality of the participants was improved and also they were able to maintain their sleep for ideal timing.

\section{CONCLUSION}

Back pain is a very big problem in today's growing world. This problem can also be seen at large context in IT sector. Because of same body posture for long hour and continuous stress on spine, many employees suffer from chronic back pain. This health condition leads them to poor life quality, less productivity and restricts them from doing many works $\&$ travelling than they usually do. Yoga is very helpful in chronic back pain management and in improving life quality. In this paper, it was revealed that yoga is a great therapy for people who are suffering from chronic back pain. It is adaptable for IT sector personnel. Yoga is costeffective and convenient tool for organizations (Devi \& Sheetal 2020). Yoga is beneficial in curing short-term and long-term back pain (Goode et al. 2016). Yoga reduces functional disability and a very good treatment therapy for low back pain (McKivigan 2017). IT professionals can use yoga for treatment of mild \& chronic back pain, because it's convenient at workplace and home as well. IT companies should organize yoga classes by experts for their employees. So that the employees can get rid of back pain, stress \& work burden etc. This kind of research can be further organized at broad level to identify more reliable results. Yoga can be used in curing different health conditions and further research regarding the same can be done at different levels.

\section{REFERENCES}

[1] Aboagye, E., Karlsson, M. L., Hagberg, J., \& Jensen, I., (2015). Cost-effectiveness of Early Interventions for Nonspecific Low Back Pain: A Randomized Controlled Study
Investigating Medical Yoga, Exercise Therapy and Self-care Advice. Journal of Rehabilitation Medical. 47, 167-173.

[2] Bhatta, J., Tekur, P., Tikhe, S. G., \& Nagendra, H. R. (2015). Yoga reduces chronic low back pain: An innovative approach. Yoga Mimamsa, 47(1), 6-9.

[3] Chang, D. G., Holt, J. A., Sklar, M., \& Groessl, E. J. (2016). Yoga as a treatment for chronic low back pain: a systematic review of the literature. Journal of orthopedics \& rheumatology, 3(1), 1-8.

[4] Devi, N., \& Sheetal. (2020). A Study to Overcome the Problem of Organizational Productivity with Yogic Interventions. International Journal for Research in Engineering Application \& Management, 6(2), 4-8.

[5] Devi, N., \& Sheetal. (2020). Effectiveness of yoga in stress management at workplace: A systematic review. International Journal of Emerging Technologies and Innovation Research, 7(4), 546-555.

[6] Goode, A. P., et al. (2016). An evidence map of yoga for low back pain. Complementary Therapies in Medicine, 25, 170177.

[7] Jadhav, A., Biradar, V., \& Bansode, N. (2020). Role of yoga in the clinical management of low back pain- a review. Ayurline: International Journal of Research in Indian Medicine, 4(1), Retrieved from http://www.ayurline.in/index.php/ayurline/article/view/313

[8] McKivigan, J. M. (2017). Efficacy of Yoga therapy in treating low back pain. Annals of Yoga and Physical Therapy, 2(4). $\quad$ Retrieved from https://touroscholar.touro.edu/chhs_pubs/34

[9] Sawyer, A. M., Martinez, S. K., \& Warren, G. L. (2012). Impact of Yoga on Low Back Pain and Function: A Systematic Review and Meta-Analysis. Journal of Yoga and Physical Therapy. 2(4), 120.

[10] Sheetal. (2020). An empirical study on effect of yogic regime on hypothyroidism with special reference to Delhi. International Journal of Multidisciplinary Educational Research, 4(7), 164-171.

[11] Sheetal. (2020). An experimental study on obesity and weight management with special reference to yoga practices. International Journal of Physical Education, Sports and Health, 7(2), 269-272.

[12] Shivaji, K. K. (2019). Effectiveness of yoga therapy on low back pain among women. Public Health Open Access, 3(1), $1-4$.

[13] Sunil, P., \& Kumari, S. (2016). Effect of yoga module on low back pain in information technology professionals. International Journal of Educational and Psychological Researches, 2(4), 234-237.

[14] Tilbr, H. E., Chuang, L. H. \& Trewhela, A. (2011). Yoga for chronic low back pain. Annals of Internal Medicine. 155(9), 569-580. 